\section{(6) OPEN ACCESS}

\title{
Familial genetic risks: how can we better navigate patient confidentiality and appropriate risk disclosure to relatives?
}

\author{
Edward S Dove, ${ }^{1}$ Vicky Chico, ${ }^{2}$ Michael Fay, ${ }^{3}$ Graeme Laurie, ${ }^{1}$ \\ Anneke M Lucassen, ${ }^{\oplus, 5}$ Emily Postan ${ }^{1}$
}

'School of Law, University of Edinburgh, Edinburgh, UK ${ }^{2}$ School of Law, University of Sheffield, Sheffield, UK

${ }^{3}$ School of Law, Keele University, Keele, UK

${ }^{4}$ Faculty of Medicine, University of Southampton, Southampton, UK

${ }^{5}$ Wessex Clinical Genetics Service, University Hospital Southampton NHS Foundation Trust, Southampton, UK

\section{Correspondence to} Edward S Dove, School of Law, University of Edinburgh, Edinburgh EH8 9YL, UK; edward.dove@ed.ac.uk

Received 26 October 2018 Revised 7 March 2019 Accepted 12 March 2019 Published Online First 23 May 2019

\section{Check for updates}

(c) Author(s) (or their employer(s)) 2019. Re-use permitted under CC BY-NC. No commercial re-use. See rights and permissions. Published by BMJ.

To cite: Dove ES, Chico V, Fay $M$, et al. J Med Ethics 2019;45:504-507.

\section{ABSTRACT}

This article investigates a high-profile and ongoing dilemma for healthcare professionals (HCPs), namely whether the existence of a (legal) duty of care to genetic relatives of a patient is a help or a hindrance in deciding what to do in cases where a patient's genetic information may have relevance to the health of the patient's family members. The English case $A B C v S t$ George's Healthcare NHS Trust and others considered if a duty of confidentiality owed to the patient and a putative duty of care to the patient's close relatives could coexist in this context. This article examines whether embracing the concept of coexisting duties could enable HCPs to respect duties in line with their clinical judgement, thereby providing legal support and clarity to professionals to allow them to provide the best possible genetics service to both the patient and their family. We argue that these dual duties, framed as a novel, composite duty to consider the interests of genetic relatives, could allow HCPs to exercise and act on their professional judgements about the relative value of information to family members, without fears of liability for negligence or breach of confidence.

The dilemma of whether, and how, to communicate familial genetic risk beyond the confines of a single patient-doctor relationship has been a challenging ethicolegal issue for many years and is much discussed in the literature. ${ }^{1-7}$ The issue is of growing, contemporary importance due to developments in clinical genetics and genomics where many more familial tendencies can now be identified through testing than compared with even a decade ago; in turn, more effective treatments are being developed through genetics and genomics. ${ }^{8}$ The dilemma is also of growing importance as signalled by the integration of genetics and genomics research into routine healthcare, ${ }^{9-11}$ seen for example, by the recent launch of a National Health Service (NHS) Genomic Medicine Service within NHS England. ${ }^{12}$ One of the most pressing unresolved issues is in which circumstances, if any, should healthcare professionals (HCPs) owe a legal duty to communicate this genetic risk information to relevant family members. Against the backdrop of recent legal developments in the UK, this article focuses on the specific question of whether the existence of a duty of care to the relatives of a patient is a help or a hindrance in deciding whether to disclose genetic information to patients' relatives or to protect the patient's confidence.
Professional guidance recognises the tensions between the interests of patients and their relatives and provides that it may be justified for an HCP to breach confidence where the aversion of harm by the disclosure substantially outweighs the claim to confidentiality. ${ }^{13}{ }^{14}$ In other words, HCPs can disclose genetic risk information without fear of professional sanction. However, the law obstructs the exercise of this professional discretion by recognising only a legal duty to protect patient confidence and not a duty to consider and act in line with the interests of third parties, where professionals conclude that these interests deserve priority. Thus, the discretion afforded in the professional guidance becomes ineffective because of the lack of legal protection, if that discretion is exercised in favour of disclosure. While there are many parallels with other disclosure dilemmas, such as those relating to sexually transmitted diseases, the perceived concern about genetic matters may be why there is a need to introduce a further legal 'duty of care' on HCPs, that is, a duty whose reasonable professional standard may entail disclosure of risk information to genetic relatives. But, would coexisting duties of care to relatives and confidentiality to patients help or hinder HCPs? And would this create certainty or simply deeper dilemmas?

Lucassen and Gilbar have argued that, in light of recent case law, in many instances, appropriate relatives can be alerted by HCPs without a breach of confidence of clinical information. ${ }^{1}$ Building on earlier work from Parker and Lucassen, ${ }^{15}$ they delineate a 'third way' for disclosure that does not require a breach of confidence as they argue HCPs are disclosing familial rather than individual information. Here, we build on this recent literature by delineating the legal structure within which a duty of care to third parties might operate. We examine the legal and professional perspectives to provide greater clarity and certainty for HCPs in navigating this dilemma. We argue that an HCP's duty of care to third parties should not be seen as being in opposition to a duty of confidentiality. Rather, if the duties coexist in a manner that reflects professional standards, then there are good reasons to believe that clinicians could provide better care to the patient and to their family.

Our claim in this article is that the coexisting duties can be framed as a 'duty to consider' the interests of at-risk genetic relatives, alongside the patient's interest in confidentiality. The professional would then come under a duty to respect whichever 
of these interests, in their professional opinion, deserves to be prioritised, as opposed to opting for the duty that they believe is least likely to result in legal action against them. Of course, many of the situations where professionals have to balance these competing duties will not be straightforward. In these circumstances, HCPs regularly engage in multidisciplinary case meetings where such cases will be carefully considered and a position reached which a professional should be able to justify in the face of competing legal duties.

\section{A DUTY OF CARE TO A PATIENT'S GENETIC RELATIVES?}

Legal cases in the UK suggest that it is at least arguable that an HCP has a legal duty to disclose genetic risks to genetic relatives-in other words, HCPs may owe a duty of care to third parties regarding the proper management of familial genetic information. However, the precise nature and scope of this duty is as yet unclear, and some might read this to include an obligation to disclose information to relatives. While we argue below that this is not necessarily so, the prevailing uncertainty must be addressed because-whatever the interpretation-the failure to discharge such a duty ultimately may lead to a successful action in negligence.

In the recent English case of $A B C v$ St George's Healthcare NHS Trust and others,${ }^{16}$ the patient (father) was clear that he did not want his daughters to be told about his Huntington's disease diagnosis, expressing a particular concern that one of his daughters, who was pregnant, might seek an abortion. Despite questioning the wisdom of his decision, the HCPs involved did not disclose the information. The uninformed daughter went on to give birth and subsequently discovered her father's diagnosis. She brought an action claiming, among other things, that if she had known of her father's diagnosis, she would have elected to terminate her pregnancy due to her concerns about being able to parent should she develop Huntington's disease. The daughter's claim was framed as a professional legal duty to inform her of her own risks (based on those discovered in her father). The case was initially struck out by the High Court in 2015, but in 2017, the Court of Appeal suggested that a duty of care owed by HCPs to genetic relatives may indeed be possible under English law, at least in the context of a highly penetrant monogenetic disorder. As a matter of formal legal process, this hearing before the Court of Appeal was solely to determine whether an argument could be made in law in such unprecedented circumstances. That is, as a matter of legal policy, the question was, might such a duty of care be successfully argued? Even if this were so successfully argued, it would be a separate matter for the claimants to argue their own facts before the High Court.

The Court of Appeal dealt with nine separate policy arguments posed by the defendant Trust, ultimately finding that, depending on the circumstances of a case, it may be fair, just and reasonable to impose a legal duty on a clinician to inform a patient's relatives about their increased genetic risk. Lord Irwin ruled that, in a situation where professional judgement falls in favour of disclosure, it was 'not necessarily correct that the law should so clearly incentivise obligations in one direction but not the other' ([2017] EWCA Civ 336). Lord Irwin also opined that:

- The duty of confidentiality is not absolute, with both legislative and case law exceptions.

- The putative right 'not to know' certain genetic information does not preclude a duty of care; concerns about psychological harm from knowing arise already, in relation to the transmission of such information with the consent of the diagnosed patient to his or her relative.
- There may be cases in which nothing would be gained from informing a relative of the risk of transmission (eg, if the claimant was past childbearing age, there was no cure and the claimant would be frightened), in which case no duty of care may be cast; thus, the discharge of any duty of care will always require a case-by-case determination.

- Although there were no closely aligned cases in UK law to date, a duty of care to a third party has been recognised in other jurisdictions in this area; and furthermore, the development of a duty of care at common law is properly the remit of the judiciary instead of Parliament, as otherwise, the law would 'ossify'.

The case is now expected to go to trial, where the High Court will examine whether clinicians can owe a duty of care to patients' relatives to inform them about actionable genetic risks.

\section{PROFESSIONAL GUIDANCE}

Professional guidance encourages HCPs to use their professional judgement and consider whether harm to family members might be averted by disclosure of certain genetic risk information. The General Medical Council (GMC) considers that information disclosure to others without the patient's consent-in other words, a breach of confidence-is justified 'if failure to do so may expose others to a risk of death or serious harm'. ${ }^{13}$ Guidance of the Joint Committee on Genomics in Medicine deals specifically with genetic information and reiterates that confidentiality is not absolute. ${ }^{14}$ In the context of genetic information, current GMC confidentiality guidelines state that if a patient refuses to consent to information being disclosed that would benefit others (ie, genetic relatives), disclosure might still be justified 'in the public interest if failure to disclose the information leaves others at risk of death or serious harm'. ${ }^{13}$

The professional guidance recognises, therefore, that a lack of access to the information itself may carry risk of serious harm to identifiable people. Despite this position, the wording in the GMC confidentiality guidelines is rather vague with respect to key phrases such as 'public interest' and 'serious harm'; furthermore, it might be read as suggesting that resolution of the disclosure dilemma is a merely discretionary matter, rather than a core part of a professional's obligations. The public interest ground does not seem to provide an adequate legal basis for modifying the obligation of confidence in the context of the disclosure of genetic information to a patient's relatives, despite the fact that the GMC guidance makes clear that protection of private interests is also a matter of public interest. And yet, in the High Court in $A B C$, Nicol $\mathrm{J}$ seemed to rule out the ability to rely on public interest as a legal basis for setting aside the obligation of confidence when he said: 'What was put against the public interest in preserving confidence in the present context was not a public interest in disclosure, but the private interest of the Claimant' ([2015] EWHC 1394 (QB) at para 13).

Thus, there is currently no legal basis for setting aside the duty of confidentiality in order to disclose genetic risk information to relatives. If there is no clear legal basis on which to set aside this obligation, and HCPs are acutely aware of their duty of confidence to their patients, these professionals are likely to feel anxious about acting on a discretion to disclose. Even if they believe their discretionary judgement to be professionally correct, they may still be concerned about whether it will be found to be legally correct. If there were a duty of care owed to third parties that involves possible disclosure of genetic information, it would have to entail a corollary legal basis to set aside the conflicting legal duty to maintain confidence where due process 
had determined that greater weight be given to disclosure of the information. It is in the context of determining the relative weight of the respective duties that clear principles are needed to consider how they might be balanced. ${ }^{17}$ Here, the law can help to clarify such matters, as we discuss further below.

In our view, the coexistence of duties of confidentiality to patients and care to patients' relatives reflects the discretion that is afforded by professional guidance. Indeed, HCPs increasingly find an individual patient focus to be inappropriate where genetic inheritance is concerned. ${ }^{18}$ Even if relatives are not yet patients, in certain circumstances they are likely to become so. Moreover, a patient can sometimes benefit from a genetic diagnosis by providing details of presence or absence of signs or symptoms in relatives (ie, a family history); it is in some ways unfair for patients to veto disclosure of something to other family members that has been found as a result of information about family members.

The concern in some quarters, though, is that the coexistence of duties will set up an irresolvable tension for HCPs. We argue below that this is not inevitable, and indeed the two duties could coexist in a way that makes exercising difficult professional discretion easier for HCPs, and potentially improves the care afforded to those who are affected by genetic illness.

\section{Navigating the two duties}

In our view, what initially look like conflicting duties can be reconciled when we see them as each focused on the same objective: allowing the implementation of a robust professional assessment of the value of preserving patient confidence and respecting relatives' interests in disclosure, in the context of striving for an outcome that will provide the best clinical genetics service for that family to be implemented, without the fear of legal action.

Thus, the putative legal duty of care to relatives of the patient is better viewed and treated as an obligation to consider both the risks and benefits of disclosing genetic risk information, and to weigh these risks and benefits against the well-established duty of confidentiality owed to the patient to keep medical (including genetic) information secret. This robust consideration allows disclosure when justified-and not only when the patient consents. Arguably, the contours of a duty to consider the interests of relatives of the patient might only come to the fore after an HCP has encouraged their patients to notify their at-risk relatives about the genetic nature of their condition-when this is possible to do so (and indeed, professional practice demonstrates all too well that this will not always be the case). Nonetheless, in all cases our proposition of reconciling duties requires that we must chart what HCPs should consider when, despite their best efforts, patients say they refuse to notify their at-risk relatives. These dual duties, framed as a novel, composite duty to consider the interests of genetic relatives, could allow HCPs to exercise and act on their professional judgements about the relative value of information to family members, without fears of liability for negligence or breach of confidence.

Professional discretion through reliance on professional guidance alone may not offer sufficient protection to give HCPs confidence in acting against patients' wishes. Reliance must also be placed on legal duties, both to protect the interests of all parties involved, and to ensure that HCPs themselves are protected from legal actions where they have nonetheless acted within accordance with ethical and professional good practice. The law in the UK indicates that coexisting legal duties may exist, but only if they are predicated on the professional balancing exercise. We argue that the two duties should be drawn together so that legal protection tracks professional norms and practices. If a duty of care owed to relatives of the patient were to coexist alongside the established duty to maintain confidentiality of patient information, framed as a composite duty to consider the interests of the patient's relatives, HCPs would have legal protection that is tied to the professional balancing exercise of care to the patient versus a duty of care to relatives.

Instituting a legal duty of care owed to a patient's genetic relatives will place on a legal footing the kinds of professional decision-making exercises that HCPs should be undertaking anyway. In our analysis, when an HCP receives a patient's genetic information and that information may have relevance to the health of some members of the patient's family, and a patient does not consent to disclosing that information to the relevant family members, the HCP must undertake the balancing exercise and make a justifiable decision. Whether disclosure is justified will depend on the facts of the individual case, including: the condition in question; its severity; whether treatment or prevention exists; the likely age of onset; the likelihood of harm to the family members in question; and the likely personal significance of the information to these family members (a significance which-following $A B C$-may extend beyond clinical actionablity narrowly construed). Undoubtedly, disclosing genetic information to relatives of a patient over the objection of the patient carries potential costs. We emphasise, though, that a duty to consider the interests of relatives does not necessarily mean HCPs must nevertheless disclose this information, regardless of the costs. So what would such a duty entail then, and when might disclosure be justified?

\section{WHAT WOULD THE DUTY TO CONSIDER THE INTERESTS OF GENETIC RELATIVES ENTAIL?}

One may argue that the existence of a legal duty of care to genetic relatives might well lead some HCPs to bypass the professional balancing exercise and interpret this as an absolute requirement to disclose information in all circumstances, even prior to having a discussion with the patient to encourage him or her to notify at-risk relatives. This would be an unfortunate misinterpretation of the duty and constitute poor professional practice. To mitigate this risk, it is necessary to provide specificity about when the duty to consider the interests of relatives triggers an obligation to disclose information, as part of a wider range of actions that can be taken by an HCP. In this regard, we highlight the significance of the factors set out above. Moreover, precisely because this pairing of duties sharpens the focus on the health and well-being of family members, we strongly advise against equating a duty of care with a broadly constructed duty to make full, active disclosure. Instead, full, active disclosure of genetic risk information might be only one possible means of discharging this duty.

A duty to consider the interests of genetic relatives may be discharged in various ways, including, depending on the context, non-disclosure to relatives. Thus, this duty would also accommodate a possible interest in not knowing. Some relatives might prefer not to have unknown and unsolicited information thrust on them. If the HCP has a duty of care that is predicated on recognising the interests of relatives, and on using careful professional judgement in discerning when these interests are engaged, then non-disclosure must also be part of the calculus. ${ }^{19}$ Were disclosure to be considered the professionally and legally appropriate position, there are various forms that such disclosure could take. Disclosing to relatives, for example, only that certain information regarding familial genetic risk is available would mean the relatives are (potentially) empowered to act on it. Thus, this duty could sometimes be satisfied by a general indication that information is available (which 
thus may not breach confidence), or initiating discussions with other relatives who have the relevant genetic information and are willing to share it. In the case of $A B C$, for example, that would then involve telling the daughter that her father's symptomatology (that she knew about) could indicate an inherited tendency that she might want to look into.

Ultimately, a duty to consider the interests of genetic relatives would require HCPs to exercise reasonable care to ascertain the nature and extent of information provision that would best serve relatives' interests, and any possible impacts of the manner in which it is communicated, as part of determining whether disclosure is justified. ${ }^{20}$ The duty entails HCPs considering the interests of known relatives of the patient with the pertinent genetic (risk) information, and assessing whether disclosure is warranted in the particular circumstances-and if so, to whom - and whether the expected benefits of doing so outweigh the risk of harm to either the patient or the relative(s). Indeed, the general principle of data minimisation, which is one of the core principles underpinning data protection law (eg, the EU General Data Protection Regulation 2016/679 and the UK's Data Protection Act 2018), would apply to any disclosure of confidential patient information, such that only information that is necessary for the purposes of informing the relative of their risk should be disclosed.

\section{CONCLUSION}

Confidentiality is a deeply entrenched legal duty in the relationship between HCPs and their patients. Where an HCP wants to act in a way that may on the face of it breach this duty, they will want to be sure that there is a legal basis that negates that breach. In the context of healthcare, the legal basis which is usually relied on to negate a breach of confidence is consent. Where consent is not forthcoming, there is little scope for another legal basis to apply unless there is a clear risk of serious harmwhich has traditionally focused on violence ${ }^{21}$ - that allows the professional to rely on the public interest exception. As we have seen, HCPs worry that the public interest exception is not an appropriate legal basis for setting aside the duty of confidence where the HCP believes at-risk relatives should be told about relevant information, yet consent from the index patient is not forthcoming. The creation of a duty to consider the interests of genetic relatives, which in this instance would entail an obligation to disclose, would provide a legal basis for setting aside conflicting legal duties which are of lower priority. This would allow HCPs to act in line with their considered professional opinions without fear of legal action.

Confidentiality is not meant to be invariably wielded as a shield in the HCP's armament-HCPs should not default to an assumption that the patient's wishes are always the most important issue. Nor, however, should HCPs always assume that disclosure of genetic risk information to relatives is always the correct or best ethical and legal thing to do. Looking back at the $A B C$ case, it is arguable that the daughter's position and pregnancy were of greater importance than the father's desire not to share the information and as such, confidentiality could-and indeed should-have been justifiably breached.

Rather than cause anxiety for HCPs, establishing coexisting duties of care and confidentiality-framed as a composite duty to consider the interests of genetic relatives-may allow them to act more confidently in line with the discretion that professional guidance has long afforded them, without the fear of legal action for conforming to their professional judgement. In sum, HCPs should not view a duty of care to genetic relatives as a legal stick' with which they are beaten, but instead as legal protection to act in line with their existing professional best practice.

Acknowledgements The authors thank Edinburgh Law School for supporting a symposium through funding from the Law School's Research Support Fund ('Symposium on healthcare professionals' duty of care: should it extend from patients to genetic relatives?', held in June 2018) that led to the development of this article. The authors also thank the symposium participants and peer reviewers of this article for their insightful contributions and suggestions.

Contributors All authors contributed to the manuscript equally.

Funding The authors have not declared a specific grant for this research from any funding agency in the public, commercial or not-for-profit sectors.

Competing interests $A M L$ declares that she has served as an expert witness in the case of ABC v St George's Healthcare NHS Trust and others. AML is supported by a Wellcome Collaborative Award entitled 'Ethical Preparedness in Genomic Medicine' (Award No: 208053/Z/17/Z).

Patient consent for publication Not required.

Provenance and peer review Not commissioned; externally peer reviewed.

Author note This article is based on research conducted with support from a Wellcome Senior Investigator Award entitled 'Confronting the Liminal Spaces of Health Research Regulation' (Award No:WT103360MA): http://www.liminalspaces. ed.ac.uk/.

Open access This is an open access article distributed in accordance with the Creative Commons Attribution Non Commercial (CC BY-NC 4.0) license, which permits others to distribute, remix, adapt, build upon this work non-commercially, and license their derivative works on different terms, provided the original work is properly cited, appropriate credit is given, any changes made indicated, and the use is non-commercial. See: http://creativecommons.org/licenses/by-nc/4.0/.

\section{REFERENCES}

1 Lucassen A, Gilbar R. Alerting relatives about heritable risks: the limits of confidentiality. BMJ 2018:361:k1409.

2 Chico V. Non-disclosure of genetic risks: the case for developing legal wrongs. Med Law Int 2016;16:3-26.

3 Negligence FM. genetics and families: a duty to disclose actionable risks. Med Law Inter 2016;16:115-46.

4 Mitchell C, Ploem MC, Hennekam RC, et al. A duty to warn relatives in clinical genetics: arguably 'fair just and reasonable' in English law? Tottels J Prof Neglig 2016;32:120-36.

5 de Paor A. Genetic risks and doctors' disclosure obligations - revisiting the duty of confidentiality. Eur J Health Law 2018;25:365-88.

6 Rothstein MA. Reconsidering the duty to warn genetically at-risk relatives. Genet Med 2018:20:285-90.

7 Laurie G. Genetic privacy: a challenge to medico-legal norms. Cambridge: Cambridge University Press, 2002.

8 Ginsburg G, Willard H. Genomic and precision medicine: foundations, translation, and implementation. 3rd edn. London: Elsevier, 2017.

9 Department of Health and Social Care. Matt Hancock announces ambition to map 5 million genomes. 2018. https://www.gov.uk/government/news/matt-hancockannounces-ambition-to-map-5-million-genomes (accessed 7 Mar 2019).

10 National Institutes of Health. All of Us Research Program. https://allofus.nih.gov (accessed 7 Mar 2019).

11 Human Heredity and Health in Africa (H3Africa) Initiative. https://h3africa.org (accessed 7 Mar 2019).

12 NHS England. NHS Genomic Medicine Service. 2018. https://www.england.nhs.uk/ genomics/nhs-genomic-med-service/ (accessed 7 Mar 2019).

13 General Medical Council. Confidentiality: good practice in handling patient information: General Medical Council, 2017, revised in May 2018.

14 Royal College of Physicians, Royal College of Pathologists and British Society for Human Genetics. Consent and confidentiality in clinical genetic practice: guidance on genetic testing and sharing genetic information. Report of the Joint Committee on Medical Genetics. 2nd edn. London: RCP, RCPath, 2011.

15 Parker M, Lucassen AM. Genetic information: a joint account? BMJ 2004;329:165-7.

16 ABC v St George's Healthcare NHS Trust [2015] EWHC 1394 (QB); [2017] EWCA Civ 336 (CA).

17 Chico V. Reasonable expectations of privacy in non-disclosure of familial genetic risk: What is it reasonable to expect? Eur J Med Genet. In Press. 2018

18 Gilbar R, Barnoy S. Companions or patients? The impact of family presence in genetic consultations for inherited breast cancer: relational autonomy in practice. Bioethics 2018:32:378-87.

19 Laurie G. Recognizing the right not to know: conceptual, professional, and legal implications. J Law Med Ethics 2014;42:53-63.

20 Parker M, Lucassen A. Using a genetic test result in the care of family members: how does the duty of confidentiality apply? Eur J Hum Genet 2018;26:955-9.

21 Great Britain. England. Court of Appeal, Civil Division. W v. Egdell. All Engl Law Rep 1989;[1990]1:835-53. 